\title{
A Photolabile Fe Catalyst for Light-triggered Alkyd Paint Curing
}

\author{
Johan Bootsma, ${ }^{[a]}$ Wesley R. Browne, ${ }^{[b]}$ Jitte Flapper, ${ }^{[c]}$ and Bas de Bruin ${ }^{*[a]}$
}

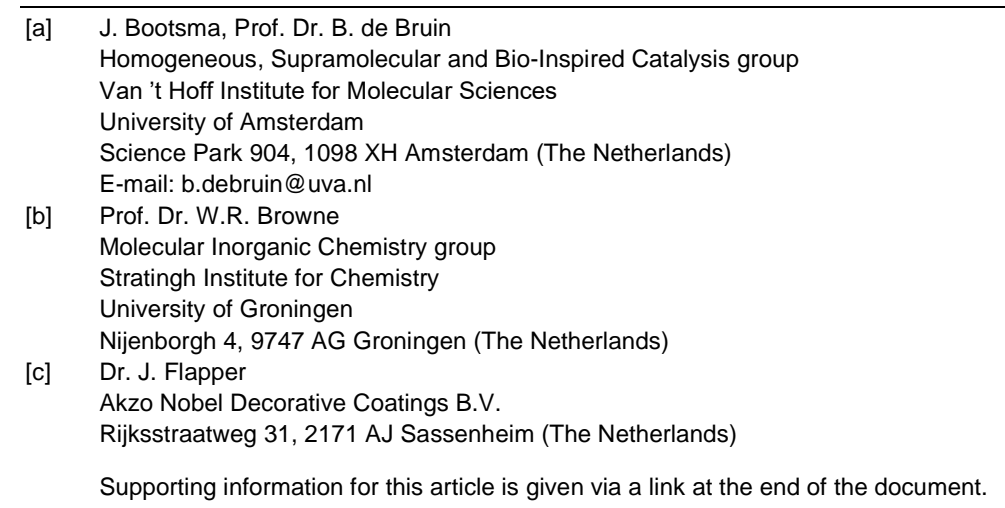

\begin{abstract}
In search for cobalt replacements for alkyd paint curing we show that the photo-active complex $\left[(\mathrm{Cp}) \mathrm{Fe}\left(\mathrm{C}_{6} \mathrm{H}_{6}\right)\right]^{+} \quad(\mathrm{Cp}=$ cyclopentadienyl) acts as a latent catalytic drier that allows for photochemical control over the onset of curing, without the need for anti-skinning agents such as the volatile MEKO normally used to prevent curing during paint storage. The highly soluble neutral complex $[(\mathrm{Cp}) \mathrm{Fe}(\mathrm{Ch})](\mathrm{Ch}=$ cyclohexadienyl) readily converts to the photo-active complex $\left[(\mathrm{Cp}) \mathrm{Fe}\left(\mathrm{C}_{6} \mathrm{H}_{6}\right)\right]^{+}$upon oxidation in alkyd, allowing the latter to be dosed in a wide range of concentrations. Infrared and Raman studies show similar spectral changes of the alkyd paint matrix as have been observed in alkyd curing mediated by the known commercial cobalt- and manganese-based driers Durham NUODEX® Cobalt $10 \mathrm{Neo}$ and NUODEX® DryCoat. The new $[(\mathrm{Cp}) \mathrm{Fe}(\mathrm{Ch})] /\left[(\mathrm{Cp}) \mathrm{Fe}\left(\mathrm{C}_{6} \mathrm{H}_{6}\right)\right]^{+}$system performs equally well as both commercial paint driers in terms of drying time, and outperforms NUODEX® DryCoat by showing a hardness development (increase) similar to the cobalt-based drier. Based on an observed light-dark on/off effect and EPR studies we propose that photolysis of $\left[(\mathrm{Cp}) \mathrm{Fe}\left(\mathrm{C}_{6} \mathrm{H}_{6}\right)\right]^{+}$generates short-lived active $\mathrm{Fe}$ "l species, explaining the excellent latency. The novel alkyd curing system [(Cp) Fe(Ch)] / $\left[(\mathrm{Cp}) \mathrm{Fe}\left(\mathrm{C}_{6} \mathrm{H}_{6}\right)\right]^{+}$presented herein is the first example of an intrinsically latent paint curing catalyst that is: (1) based on an abundant and harmless transition metal $(\mathrm{Fe})$, (2) doesn't require any anti-skinning agents, and (3) shows excellent performance in terms of drying times and hardness development.
\end{abstract}

\section{Introduction}

Stimuli-responsive (switchable) catalysts are attracting increasing attention to achieve spatial and temporal control of chemical transformations ${ }^{[1]}$ mimicking metabolic processes in living cells. ${ }^{[2]}$ Switchable catalysts also provide ample opportunities in external control of properties in material science, with photo-switching being an especially attractive functionality for future applications. [ 3 ] Indeed, light sensitive compounds and photocatalysts are used widely to initiate polymerisation reactions. ${ }^{[4,5,6]}$ Light triggered activation of latent catalysts holds tremendous potential in the amplification of external triggers but has received limited attention in achieving latency in polymer cross-linking processes, ${ }^{[7]}$ which is of particular importance to cure paint.

Alkyd resins, which are polyesters containing (unsaturated) fatty acids ${ }^{[8]}$ are produced on a multi-ton scale annually for use as the binder in paints, in which an oxidative radical-based crosslinking process leads to curing.$^{[9,10]}$ The non-catalysed process is slow and can take months to complete. Hence catalysts are added, such as metal compounds called siccatives or driers, that are based primarily on cobalt, vanadium, iron and manganese. ${ }^{[11]}$

Currently the main drier combination used for alkyds is based on cobalt to increase the drying speed, with calcium and zirconium carboxylates added to increase stability and crosslink density, respectively. ${ }^{[12]}$ Premature curing during storage, which leads to the formation of a thick polymeric layer known as a "skin" on the surface of the coating (often observed in old paint cans), is inhibited by adding anti-skinning agents such as the volatile methyl ethyl ketoxime (MEKO). However, while effective, the use of both cobalt and MEKO in paints and coatings is under legislative pressure by programmes such as the European REACH Regulation, ${ }^{[13]}$ and new driers and anti-skinning methods are required urgently.

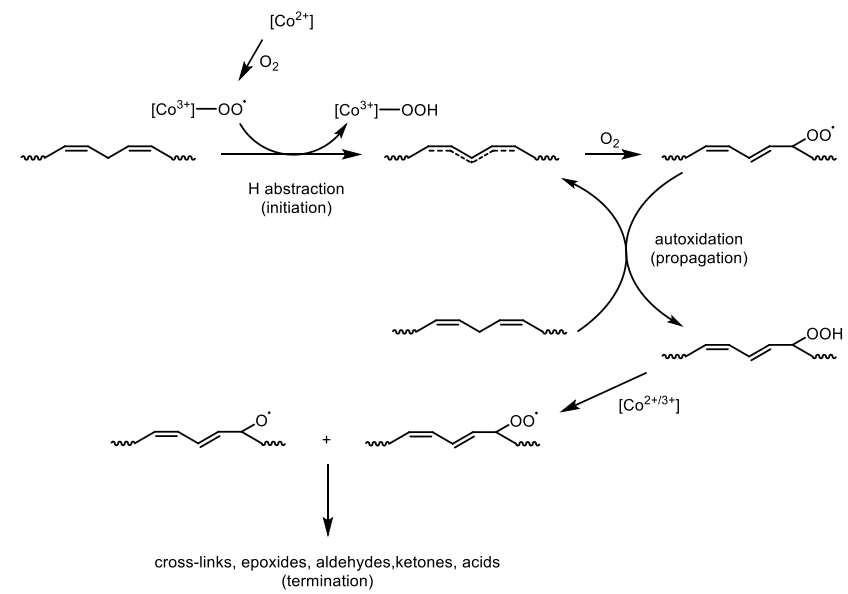

Scheme 1. Generally accepted mechanism of alkyd curing using cobalt-based driers. ${ }^{[19]}$

Alternative driers developed during the past ten years, such as manganese complexes based on the $\mathrm{Me}_{3} T A C N$ (N,N',N"trimethyl-1,4,7-triazacyclononane) ligand and iron complexes based on the bispidon ligand, ${ }^{[14,15]}$ emerged from their application 
in oxidative bleaching and stain-removal catalysis. ${ }^{[16]}$ More recently ferrocene and its substituted analogues, ${ }^{[17]}$ in particular acyl-substituted ferrocenes such as benzoyl ferrocene ${ }^{[18]}$ have shown good performance as alkyd paint driers. Their reactivity in alkyd curing is ascribed to the ferrocene/ferrocenium redox couple by analogy to the $\mathrm{Co}^{2+} / \mathrm{Co}^{3+}$ cycle proposed for cobaltbased driers (Scheme 1). ${ }^{[19]}$

Herein, we report that $\left[\left(\eta^{5}\right.\right.$-cyclopentadienyl $)\left(\eta^{6}\right.$ benzene)iron] $\left(\mathrm{PF}_{6}\right)$ (1) can be used as a visible light photoinitiated drier for alkyd paints. We show that the complex $\left[\left(n^{5}-\right.\right.$ cyclopentadienyl)( $\eta^{5}$-cyclohexadienyl)iron] (2) forms the photoactive $\left[\left(\eta^{5}\right.\right.$-cyclopentadienyl $)\left(\eta^{6} \text {-benzene)iron }\right]^{+}$complex in situ when mixed with alkyd paints under air. The spontaneous oxidation of the soluble neutral precursor allows for higher catalyst loadings in the apolar matrix than achievable directly with the cationic $\left[(\mathrm{Cp}) \mathrm{Fe}\left(\mathrm{C}_{6} \mathrm{H}_{6}\right)\right]\left(\mathrm{PF}_{6}\right)$ complex 1. This (combined) approach introduces latency through light-activation, eliminating the need anti-skinning agents such as MEKO.

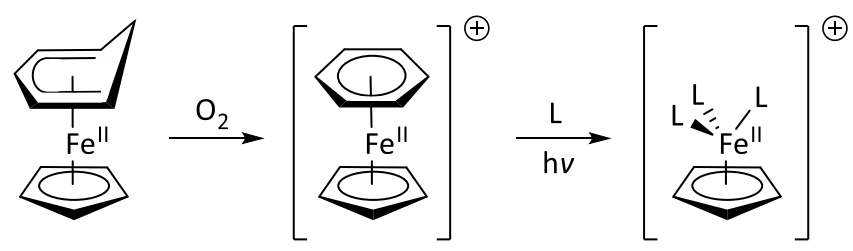

Scheme 2. Aerobic oxidation of $[(\mathrm{Cp}) \mathrm{Fe}(\mathrm{Ch})]$ (2) leads to in situ formation of $\left[(\mathrm{Cp}) \mathrm{Fe}\left(\mathrm{C}_{6} \mathrm{H}_{6}\right)\right]^{+}$, which generates an active $\mathrm{Fe}^{\prime l}$ catalyst for alkyd paint curing upon photo-activation ( $\mathrm{L}=$ solvent or substrate).

\section{Results and Discussion}

Application of $\left[(\mathrm{Cp}) \mathrm{Fe}\left(\mathrm{C}_{6} \mathrm{H}_{6}\right)\right]\left(\mathrm{PF}_{6}\right)$ (1) as a drier for Setal-270 The class of $[(\mathrm{Cp}) \mathrm{Fe}$ (arene $)]^{+}$complexes, which can be prepared from ferrocene and $\mathrm{AlCl}_{3}$ with the arene present in excess, ${ }^{[20]}$ has been used previously for photo-crosslinking of epoxy resins. ${ }^{[21]}$ The thermal and oxidative stability of these compounds, ${ }^{[20]}$ as well as the absence of strong colouring (which is important for application in paint) prompted us to evaluate their potency in alkyd curing. In particular, we anticipated that photolysis would lead to the release of an $\mathrm{Fe}(\mathrm{II})$ species that could activate oxygen to initiate $\mathrm{C}-\mathrm{H}$ activation in the cis,cis-1,4-pentadiene motif of the linoleic fatty acids, similar to the radical initiation process involved in cobalt-mediated alkyd paint curing (Scheme 1).

Initial studies examined the potency of the ionic compound $\left[(\mathrm{Cp}) \mathrm{Fe}\left(\mathrm{C}_{6} \mathrm{H}_{6}\right)\right]\left(\mathrm{PF}_{6}\right)(\mathbf{1})$ in the soybean-based alkyd Setal-270. The complex $\left[(\mathrm{Cp}) \mathrm{Fe}\left(\mathrm{C}_{6} \mathrm{H}_{6}\right)\right]\left(\mathrm{PF}_{6}\right)(\mathbf{1})$, predissolved in acetone (see ESI), is soluble in alkyd mixtures in concentrations up to 0.05 wt\% Fe w.r.t. solid binder content. (From here on all concentrations will be given as wt\% metal w.r.t. solid binder content; see also ESI.) However, with 0.06 wt\% of complex 1 precipitation took place within a few minutes after mixing, and immediately upon mixing for loadings $\geq 0.07 \mathrm{wt} \%$ (Figure 1).

The drying time for $90 \mu \mathrm{m}$ thick films of alkyd mixtures containing 1 under ambient lighting (fluorescent beam lighting + outdoor sunlight through the lab window) becomes shorter with increasing (pre)catalyst concentrations (6-7 $\mathrm{h}$ at $0.05 \mathrm{wt} \%$ 1). Importantly, mixtures of $\left[(\mathrm{Cp}) \mathrm{Fe}\left(\mathrm{C}_{6} \mathrm{H}_{6}\right)\right]\left(\mathrm{PF}_{6}\right)$ in Setal-270 stored in the dark (in absence of MEKO) did not develop a skin. These data demonstrate that $\mathbf{1}$ acts as a latent, photo-activated catalyst in alkyd paint curing. The relatively long drying times are due to the low solubility of the (pre)catalyst, which can be solved by moving to a much more soluble precursor that allows in situ formation of $\left[(\mathrm{Cp}) \mathrm{Fe}\left(\mathrm{C}_{6} \mathrm{H}_{6}\right)\right]^{+}$, in a soluble form in the resin.

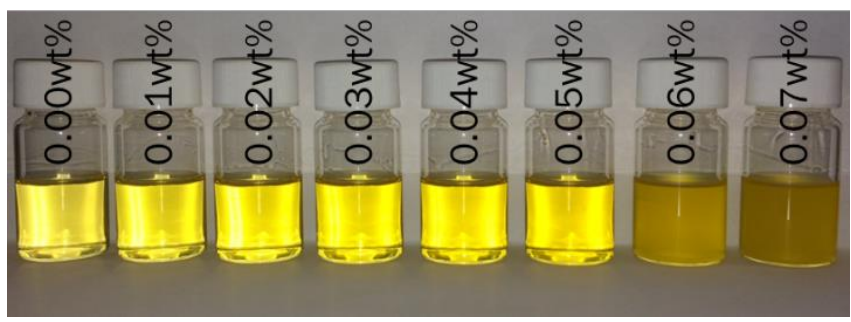

Figure 1. Addition of the complex $\left[(\mathrm{Cp}) \mathrm{Fe}\left(\mathrm{C}_{6} \mathrm{H}_{6}\right)\right]\left(\mathrm{PF}_{6}\right)$ (1) leads to a slightly more yellow colour w.r.t. the pure alkyd. It is soluble in Setal-270 up to $0.05 \mathrm{wt} \%$, above which precipitation takes place.

\section{In situ formation of $\left[(\mathrm{Cp}) \mathrm{Fe}\left(\mathrm{C}_{6} \mathrm{H}_{6}\right)\right]^{+}$from $[(\mathrm{Cp}) \mathrm{Fe}(\mathrm{Ch})](2)$}

Reduction of 1 with $\mathrm{LiAlH}_{4}{ }^{[22]}$ or $\mathrm{NaBH}_{4}{ }^{[23]}$ provides the neutral compound [( $\eta^{5}$-cyclopentadienyl $) \mathrm{Fe}\left(\eta^{5}\right.$-cyclohexadienyl $\left.)\right]$ (2). In contrast to $\mathbf{1}$, complex $\mathbf{2}$ is highly soluble in aliphatic media, and can even be dosed as a solid to the alkyd resin. Of immediate interest is whether or not the neutral complex would undergo aerobic oxidation to the cationic complex $\left[(\mathrm{Cp}) \mathrm{Fe}\left(\mathrm{C}_{6} \mathrm{H}_{6}\right)\right]^{+}$at room temperature, ${ }^{[24]}$ allowing for in situ formation of $\left[(\mathrm{Cp}) \mathrm{Fe}\left(\mathrm{C}_{6} \mathrm{H}_{6}\right)\right]^{+}$at concentrations higher than $0.05 \mathrm{wt} \%$ without precipitation.

The solubility and in situ oxidation of 2 in Setal-270 in the concentration range $0.02-0.14$ wt $\%$ of $\mathrm{Fe}$ was determined by UV/Vis absorption spectroscopy. Precipitation was not observed and the absorption spectra show the conversion of the neutral complex $[(\mathrm{Cp}) \mathrm{Fe}(\mathrm{Ch})]\left(\lambda_{\max }=414 \mathrm{~nm}\right)$ to the cationic complex $\left[(\mathrm{Cp}) \mathrm{Fe}\left(\mathrm{C}_{6} \mathrm{H}_{6}\right)\right]^{+}\left(\lambda_{\max }=452 \mathrm{~nm}\right)$ (Figure 2). Both the spectra and linear fits of the Lambert-Beer law plots (slope: 6.0 vs. 6.1 for Setal-270 dosed with 2 and $\mathbf{1}$, respectively) unambiguously support the in situ transformation of 2 into $\left[(\mathrm{Cp}) \mathrm{Fe}\left(\mathrm{C}_{6} \mathrm{H}_{6}\right)\right]^{+}$.

When $2\left(\eta^{5}-\mathrm{C}_{5} \mathrm{H}_{5}: 4.27 \mathrm{ppm}\right)$ was mixed with a degassed solution of Setal-270 in heptane in a $\mathrm{N}_{2}$-filled glovebox, only minor oxidation to the cationic complex $\left(\eta^{5}-\mathrm{C}_{5} \mathrm{H}_{5}: 4.93 \mathrm{ppm}\right)$ was observed. ${ }^{1} \mathrm{H}$ NMR spectra in $\mathrm{CDCl}_{3}$ of a sample exposed to air overnight showed broadened signals around $6.30 \mathrm{ppm}\left(\eta^{6}-\mathrm{C}_{6} \mathrm{H}_{6}\right)$ and $5.08 \mathrm{ppm}\left(\mathrm{n}^{5}-\mathrm{C}_{5} \mathrm{H}_{5}\right)$, and disappearance of the signals belonging to 2 , indicating complete transformation of $[(\mathrm{Cp}) \mathrm{Fe}(\mathrm{Ch})]$ to $\left[(\mathrm{Cp}) \mathrm{Fe}\left(\mathrm{C}_{6} \mathrm{H}_{6}\right)\right]^{+}$(Figure S5.)

\section{Drying time performance and time-resolved FTIR and Raman spectroscopy}

Drying times for full formulations (incl. secondary driers based on zirconium and calcium) under controlled temperature (23 or $10^{\circ} \mathrm{C}$ ), humidity (50 and $85 \%$ relative humidity, respectively) and illumination $\left(23^{\circ} \mathrm{C}: 116 \mathrm{Lux}, 10^{\circ} \mathrm{C}\right.$ : $\left.190 \mathrm{Lux}\right)$ showed that the rate of curing increases upon increasing the concentration of 2 , with drying times of ca. $3 \mathrm{~h}$ for concentrations $\geq 0.10 \mathrm{wt} \%$ (Figure S3). These drying times are comparable to those for the commercial driers NUODEX® Cobalt $10 \mathrm{Neo}$ (cobalt neodecanoate) and NUODEX® DryCoat (a complex of $\mathrm{Mn}$ and $\mathrm{Me}_{3} \mathrm{TACN}$ ), which are typically dosed at $0.125 \mathrm{wt} \%$ Co and $0.0125 \mathrm{wt} \% \mathrm{Mn}$ w.r.t. solid binder, respectively.

Curing with 2 only takes place upon continued exposure of the film of paint to light, and samples held in the dark fail to 
undergo curing. Notably, films held in the dark for $18 \mathrm{~h}$ or $24 \mathrm{~h}$ cured in the same time once exposed to light (Figure S3). These results contrast with those obtained with NUODEX® Cobalt 10 Neo and NUODEX® DryCoat, which undergo curing at a similar rate in the dark as under light.
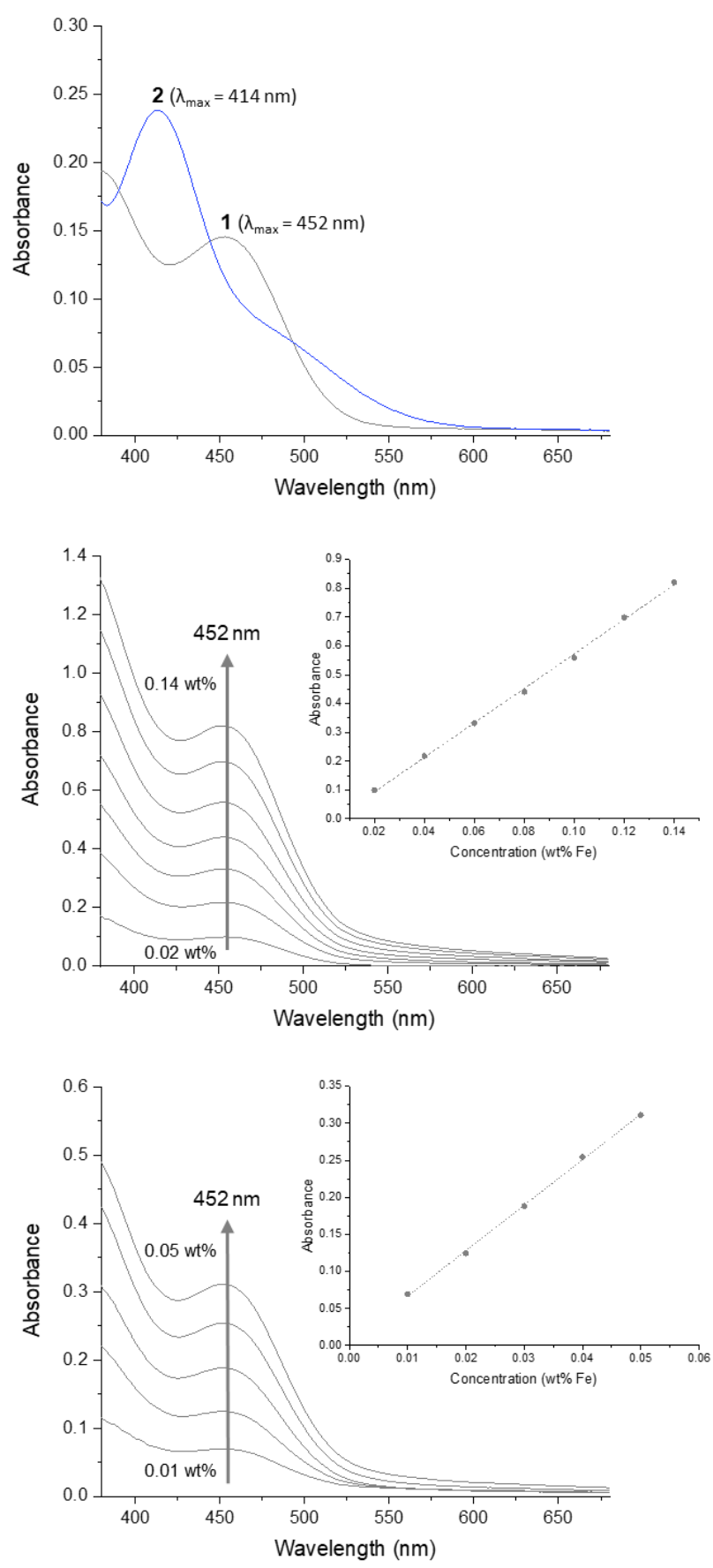

Figure 2. UV/Vis absorption spectra of (top) 1 and 2 in $\mathrm{CH}_{3} \mathrm{CN}$ and hexane, respectively, (middle) 2 (0.02-0.14 wt\% Fe) in Setal-270 and (bottom) 1 (0.01$0.05 \mathrm{wt} \% \mathrm{Fe}$ ) in Setal-270. Measurements performed under aerobic conditions.

Time-resolved FTIR and Raman spectroscopy show the same spectral changes of the alkyd paint matrix during curing of Setal-270 dosed with 2 as with the commercial driers NUODEX® Cobalt $10 \mathrm{Neo}$ and NUODEX® DryCoat. Consumption of cisalkene $\left(3008 \mathrm{~cm}^{-1}\right)$ and formation of (conjugated) trans-alkene $\left(987 \mathrm{~cm}^{-1}\right)$ as well as a hydroxylated species $\left(3400 \mathrm{~cm}^{-1}\right)$ is observed by FTIR spectroscopy, ${ }^{[25]}$ and consumption of $\mathrm{C}=\mathrm{C}$ bonds $\left(1656,1265 \mathrm{~cm}^{-1}\right)$ is observed by Raman spectroscopy (Figures 3, S8, and S14). ${ }^{[33]}$
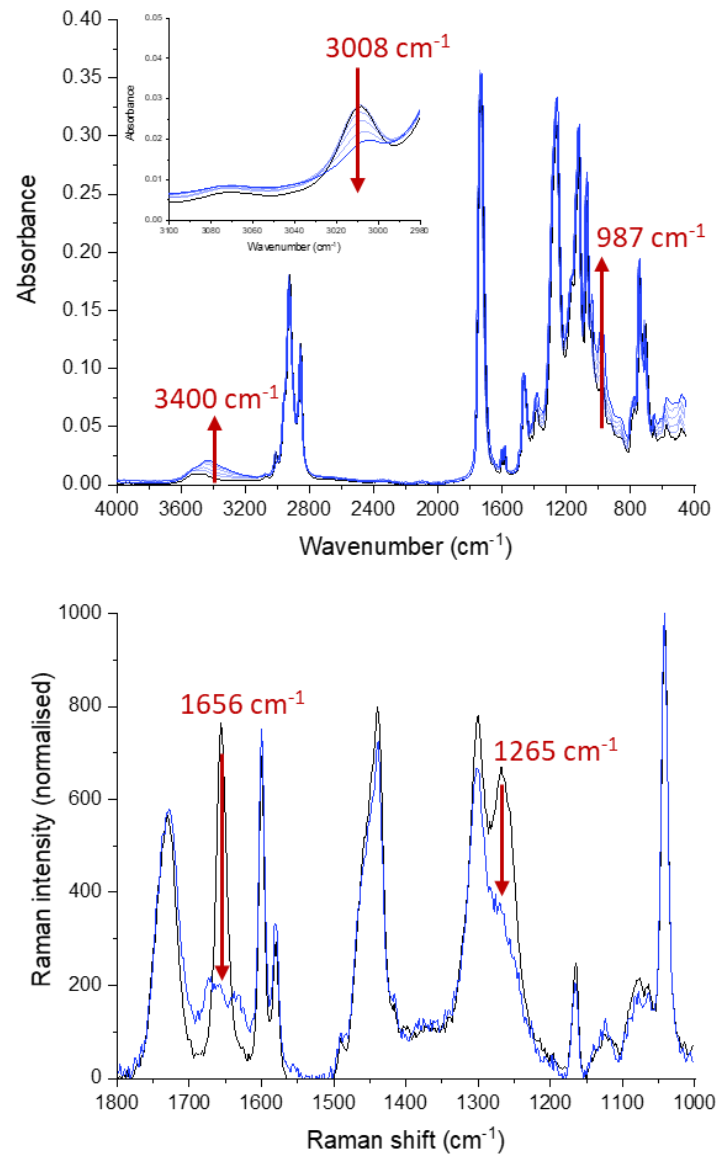

Figure 3. FTIR (top) and Raman (bottom) spectra showing curing of Setal-270 with $[(\mathrm{Cp}) \mathrm{Fe}(\mathrm{Ch})](0.10 \mathrm{wt} \%)$.

\section{Dependence of latency \& curing on light}

The impact of the primary inner-filter effect on the efficiency of photo-activation and drying rates through the films were probed by UV/Vis absorption spectroscopy. Regardless of the applied concentrations $(0.0-0.14$ wt\% Fe), $90 \mu \mathrm{m}$ thick films show $~ 98-$ $99 \%$ transmission in the visible region and hence light transmission is not a limiting factor for photo-activation (Figure S7).

$90 \mu \mathrm{m}$ thin films of Setal-270 dosed with 0.10 wt\% 2 were exposed to a short flash of broad band irradiation either once or several times. The samples were left in the dark for 30 min after each flash and characterised by FTIR spectroscopy, with the conversion of the starting material manifested in a decrease in the band at $3008 \mathrm{~cm}^{-1}$ (cis-C=C-H) characteristic for the unsaturated fatty acids. ${ }^{[25]}$ Neither a single nor repeated flashes led to significant conversion, just as for control samples kept in the dark for the same periods (Figure S9).

Thin films, which were held in the dark and then exposed to light for $30 \mathrm{~min}$ periodically, showed a clear on/off effect with 
significant conversion observed only after periods of illumination (Figure 4). Films exposed to light for 90 min continuously show halting of conversion once the samples were placed in the dark compared to samples kept under illumination (Figure S10).

Since conversion in the dark was minor, it seems likely that the species formed after photoactivation decay into one or more species of low activity. These are presumably iron carboxylate complexes formed by coordination of the residual acid groups of the alkyd to photogenerated $\left[\mathrm{Fe}^{\prime \prime}(\mathrm{Cp})\right]^{+}$species. In this perspective it is noteworthy that iron carboxylates have a low activity in alkyd curing at room temperature. ${ }^{[15]}$ This rationalises the decrease in rate and reduced conversion in the dark after periods of illumination - although at this moment we cannot fully exclude an equilibrium between (photo-)activated species and a (photo-)resting state.

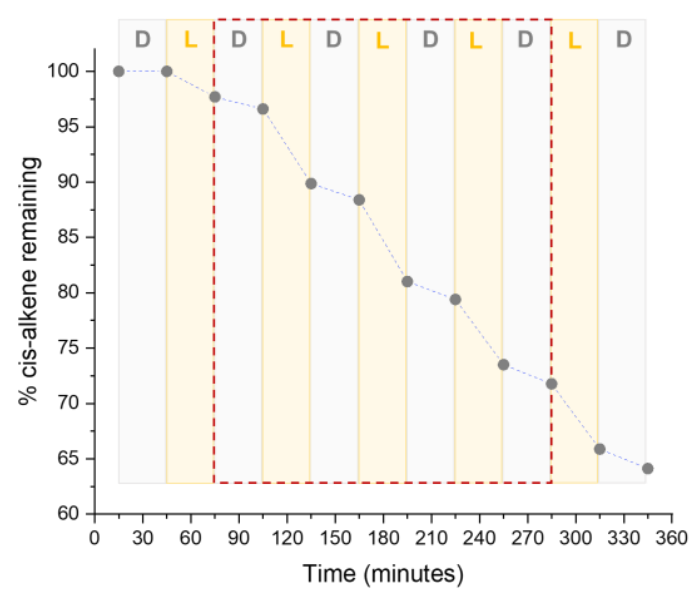

Figure 4. Switching between 30 min periods of dark (D) and light (L) shows an on/off effect on conversion and hence the necessity for continuous irradiation, most apparent in the highlighted central area.

The results indicate that catalyst activation is a gradual process and that continuous irradiation is required to maintain a steady state concentration of the active species and thereby a stable curing rate over the entire drying period. This model rationalises the excellent latency and skin-free storage of paint formulations with complex $\mathbf{2}$ as the drier in a regular metal paint can. In fact, a sample stored for 2 months showed little difference in conversion rate to a freshly prepared sample, and samples stored for $\sim 9.5$ and $\sim 12.5$ months still showed excellent curing behaviour (Figure S11).

\section{Photolysis of the cationic complex}

Photolysis of $\left[(\mathrm{Cp}) \mathrm{Fe}\left(\mathrm{C}_{6} \mathrm{H}_{6}\right)\right]\left(\mathrm{PF}_{6}\right)(\mathbf{1})$ in acetonitrile solution leads to loss of the arene and formation of a transient $\left[(\mathrm{Cp}) \mathrm{Fe}\left(\mathrm{NCCH}_{3}\right)_{3}\right]^{+}$species, which undergoes ligand exchange to form ferrocene and $\left[\mathrm{Fe}(\mathrm{NCMe})_{6}\right]\left(\mathrm{PF}_{6}\right)_{2} \cdot{ }^{[26]} \mathrm{A}$ degassed solution of 1 in acetonitrile under ambient laboratory light showed an exponential decrease in absorbance, as expected for a photochemical displacement reaction, with a close to linear decay in the first $7 \mathrm{~h}$ (Figure S4).

Photolysis in Setal-270 also showed a linear release of $\mathrm{C}_{6} \mathrm{H}_{6}$ over $6 \mathrm{~h}$ (Figures 5 and S6). However, formation of ferrocene was not observed in Setal-270 and minor amounts of cyclopentadiene
$(\mathrm{CpH})$ were formed, thus suggesting that the $\mathrm{Cp}$ ligand remains mostly bound to iron after photo-activation in the alkyd matrix.

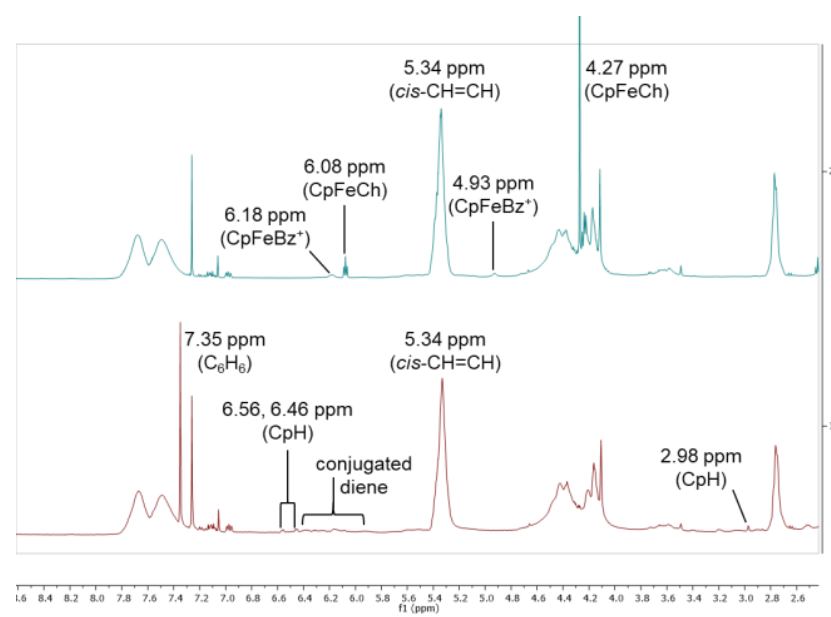

Figure 5. ${ }^{1} \mathrm{H}$ NMR spectrum (top) of 2 in degassed Setal-270 prepared under $\mathrm{N}_{2}$ and (bottom) after exposure to air and light.

Photo-induced loss of arene from [(Cp)Fe(arene) $]^{+}$ complexes has been proposed to take place from the triplet exited state, formed by intersystem crossing from the initially formed singlet excited state. ${ }^{[27]}$ Irradiation of $\mathbf{1}$ in a frozen THF glass under anaerobic conditions in the cavity of an EPR spectrometer resulted in an EPR signal characteristic for an $S=2$ (high spin) $\mathrm{Fe}^{\prime \prime}$ species (Figure $\mathrm{S18}$ ), most likely a $[(\mathrm{Cp}) \mathrm{Fe}(\mathrm{L})]^{+}$species $(\mathrm{L}=$ solvent), in line with earlier reports of an $S=2$ spin state for (coordinatively unsaturated) mono-CpFe" complexes. ${ }^{\text {[28] }}$

Freshly dried paint samples (after 1 day of curing) reveal similar (but not identical) $S=2$ signals, together with smaller amounts of $S=5 / 2$ signals characteristic for high spin $\mathrm{Fe}^{\text {III }}$ ions present in $\mathrm{Fe}_{2} \mathrm{O}_{3}$ nanoparticles. A major part of the iron species present in these freshly prepared samples thus seem to be in the high spin Fe" configuration (Figure S17). The $S=2$ EPR signals disappear over time, and in older dried paint samples only the $S$ $=5 / 2$ signals characteristic for $\mathrm{Fe}_{2} \mathrm{O}_{3}$ remain (in increased intensity; Figure S19).

The combined NMR and EPR data thus suggest that during paint curing high spin $[(\mathrm{Cp}) \mathrm{Fe}(\mathrm{L})]^{+}$species are formed, and the dependence of curing on their continued formation indicate that these species are responsible for aerobic paint curing process. In the (freshly) cured paint samples these species are most likely trapped in an inactive (or poorly active) form, presumably as (coordinatively saturated) carboxylate adducts.

\section{Kinetics of curing}

The onset of curing, as well as the continuation of the radical process, was monitored through the conversion of cis-alkene by FTIR spectroscopy (3008 $\mathrm{cm}^{-1}$, cis-C=C-H). ${ }^{[25]}$ Curing of $90 \mu \mathrm{m}$ films was followed by transmission FTIR spectroscopy using the known driers NUODEX® Cobalt $10 \mathrm{Neo}$ and NUODEX® DryCoat (both dosed with MEKO). An induction period of 50-60 min was observed after which conversion starts and accelerates in the following 60-90 min, which is indicative of a burst in formation of free radical species involved in a radical-chain auto-oxidation process (Figure 6). 
For the $[(\mathrm{Cp}) \mathrm{Fe}(\mathrm{Ch})] /\left[(\mathrm{Cp}) \mathrm{Fe}\left(\mathrm{C}_{6} \mathrm{H}_{6}\right)\right]^{+}$system described here, such behaviour is not observed. Instead, conversion shows a weak exponential, near linear decrease of the concentration of the cis-alkene (see Figure 6), coinciding with the near linear rate of photo-induced loss of $\mathrm{C}_{6} \mathrm{H}_{6}$ from $\left[(\mathrm{Cp}) \mathrm{Fe}\left(\mathrm{C}_{6} \mathrm{H}_{6}\right)\right]^{+}$in Setal-270 (Figure S6).

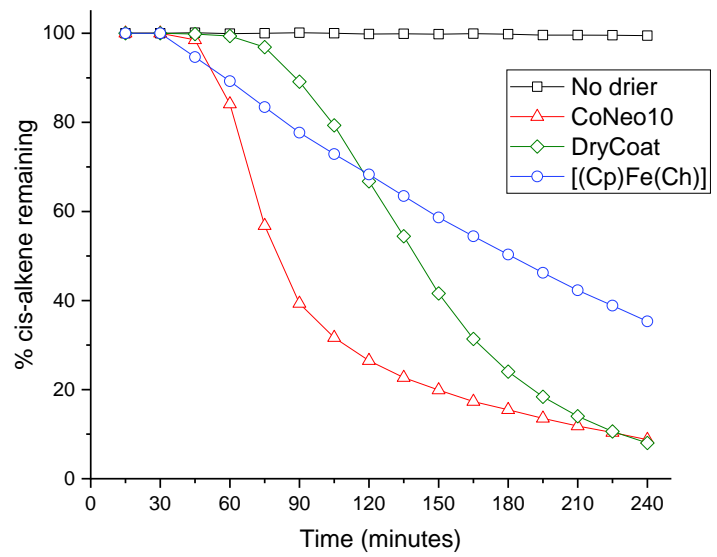

Figure 6. Conversion of cis-alkene in Setal-270 for three driers (catalysts) followed by decrease in absorbance at $3008 \mathrm{~cm}^{-1}$.

Combined with the observed on/off effect (Figure 4), the linear consumption of alkene, apparent from Figure 6, probably arises from continuous generation of new active species (most likely $[(\mathrm{Cp}) \mathrm{Fe}(\mathrm{L})]^{+}, \mathrm{L}=$ alkyd donor based on the EPR studies) by irradiation of $\left[(\mathrm{Cp}) \mathrm{Fe}\left(\mathrm{C}_{6} \mathrm{H}_{6}\right)\right]^{+}$. These species deactivate quickly resulting in a steady-state concentration of active iron species during curing. Interestingly, the dependence of the curing rate on the concentration of 2 (Figure S13) shows a broken order in [Fe] $\left(\right.$ rate $\left.=\mathrm{k}_{\mathrm{obs}}[\mathrm{Fe}]^{0.5}\right)$. This implies that a dinuclear iron complex, such as $[(\mathrm{Cp}) \mathrm{Fe}(\mu-\mathrm{L}) \mathrm{Fe}(\mathrm{Cp})]$ ( $\mu-\mathrm{L}=$ bridging ligand, e.g. ester or carboxylate) or $\left[(\mathrm{Cp}) \mathrm{Fe}\left(\mu-\mathrm{O}_{2}\right) \mathrm{Fe}(\mathrm{Cp})\right]$, is formed, which breaks-up into active mononuclear species before the rate limiting step(s) involved in aerobic paint curing. However, the overall kinetics of this system are complex, and a interplay between the elementary steps of paint curing, $\mathrm{O}_{2}$ diffusion and the rate of the photoactivation process cannot be excluded.

\section{Hardness development and confocal Raman microscopy}

Besides decreasing the drying time, new driers should also provide a hard coating. Hardness development of coatings dried using NUODEX® Cobalt 10 Neo, NUODEX® DryCoat and 2 was assessed using a pendulum damping test, where the number of oscillations needed to reduce from an initial deflection of $6^{\circ}$ to $3^{\circ}$ were measured.

Films prepared using $[(\mathrm{Cp}) \mathrm{Fe}(\mathrm{Ch})]$ (2) show a hardness increase comparable to coatings cured with NUODEX® Cobalt 10 Neo. Coatings cured with the Mn-based NUODEX® DryCoat catalyst do not show this (see Table 1 and Table S1, ESI); in fact, softer coatings are a common drawback of known cobalt-free alkyd driers. ${ }^{[15]}$ To the best of our knowledge, this is the first ironbased alkyd drier that achieves hardness-values comparable to cobalt-based driers.
Table 1. Hardness values (number of oscillations) for $90 \mu \mathrm{m}$ paint films cured using NUODEX® Cobalt 10 Neo, NUODEX® DryCoat and [(Cp)Fe(Ch)] (2), using the König pendulum test.

\begin{tabular}{ccccc}
\hline Time $^{[\mathrm{a}]}$ & $\begin{array}{c}\text { Cobalt 10 } \\
\text { Neo }\end{array}$ & $\begin{array}{c}\text { DryCoat } \\
(\mathrm{Mn})\end{array}$ & {$[(\mathrm{Cp}) \mathrm{Fe}(\mathrm{Ch})]^{[\mathrm{b}]}$} & {$[(\mathrm{Cp}) \mathrm{Fe}(\mathrm{Ch})]^{[\mathrm{cc}]}$} \\
\hline 1 day & 15 & 13 & 13 & 14 \\
4 days & 21.5 & 13 & 16 & 18.5 \\
7 days & 24.5 & 13 & 18.5 & 21.5 \\
14 days & 29.5 & 13 & 21.5 & 26.5 \\
$100 \mathrm{~h} @$ & 40 & 15 & 30.5 & 38.5 \\
$50^{\circ} \mathrm{C}^{[\mathrm{d}]}$ & & & & \\
\hline
\end{tabular}

[a] The samples were stored at $23^{\circ} \mathrm{C}$ and $50 \%$ relative humidity. [b] Dosed at 0.10 wt \% Fe. [c] Dosed at 0.20 wt $\%$ Fe. [d] Samples were kept at $50^{\circ} \mathrm{C}$ for 100 $\mathrm{h}$ after 14 days at initial conditions.

Earlier studies with solid state NMR spectroscopy suggested that hardness increase over time with cobalt-based driers is due to a "front-forming" mode of curing. With NUODEX® Cobalt $10 \mathrm{Neo}$ a solid film forms on top of the coating with hardening developing through the film as the curing progresses (front-forming curing), whereas for NUODEX® DryCoat there is no such difference between the top and bulk of the coating (homogeneous curing). ${ }^{[29]}$ A depth profile study using confocal Raman microscopy revealed for Cobalt 10 Neo that alkene conversion (1656 $\mathrm{cm}^{-1}$ band) at the top of the film was indeed faster than deeper in the film, while such a strong depthdependence was not observed when using DryCoat. ${ }^{[30]}$ Due to the correspondence of the results from solid state NMR spectroscopy and confocal Raman microscopy the disappearance of double bonds was directly connected to the formation of crosslinks, and hence the authors concluded that front-forming curing leads to an intrinsically higher cross-linking density than homogeneous curing. ${ }^{[31]}$ However, based on the results obtained with the new Fe-based drier 2 we now come to a different conclusion.

Raman spectra recorded during curing with Cobalt $10 \mathrm{Neo}$ and DryCoat as the driers show an initial increase in Raman scattering at $1656 \mathrm{~cm}^{-1}$, followed by a gradual decrease (Figure S15). The initial increase at $1656 \mathrm{~cm}^{-1}$ is due to formation of a conjugated diene (with an intrinsically higher Raman scattering cross-section) from the linoleic and linolenic non-conjugated dienes, ${ }^{[32,33]}$ which occurs upon hydroperoxide formation in the initiation and propagation steps of alkyd curing (Scheme 1). This behaviour was not reported in the earlier study by Oyman et al. ${ }^{[30]}$

The results from our depth profile studies using confocal Raman microscopy are in accordance with literature, showing front-forming curing for NUODEX® Cobalt $10 \mathrm{Neo}$ and homogeneous curing for NUODEX® DryCoat. For the new $[(\mathrm{Cp}) \mathrm{Fe}(\mathrm{Ch})] /\left[(\mathrm{Cp}) \mathrm{Fe}\left(\mathrm{C}_{6} \mathrm{H}_{6} \mathrm{H}\right)\right]^{+}$system we do not observe a depth-dependence of the curing process (i.e. homogeneous curing), as observed for DryCoat (Figure S16). This is remarkable as the paint layers dosed with $[(\mathrm{Cp}) \mathrm{Fe}(\mathrm{Ch})](2)$ can reach much higher hardness values than those dosed with NUODEX® DryCoat. Therefore, the assumption that front-forming curing leads to harder paint layers, while homogeneous curing leads to softer materials is incorrect, or at least not generally applicable.

A possible explanation for the unusual hardness development of paints cured with Fe-based drier 2 is that the timescale of the Raman experiments $(<24 \mathrm{~h})$ may not be 
representative of the molecular changes taking place in the alkyd as the hardness increases, which proceeds over several days to weeks. Possibly, for the $[(\mathrm{Cp}) \mathrm{Fe}(\mathrm{Ch})] /\left[(\mathrm{Cp}) \mathrm{Fe}\left(\mathrm{C}_{6} \mathrm{H}_{6}\right)\right]^{+}$system the slow release of active iron, even after the coating feels dry, results in continuous photo-induced formation of active species during the curing process, thus leading to more crosslinks despite the homogeneous curing process. Ring-opening of epoxides formed during the curing ${ }^{[19]}$ by photo-activated $\left[(\mathrm{Cp}) \mathrm{Fe}\left(\mathrm{C}_{6} \mathrm{H}_{6}\right)\right]^{+}$could also lead to additional crosslinks. ${ }^{[21]}$

\section{Conclusion}

We have shown that the $[(\mathrm{Cp}) \mathrm{Fe}(\mathrm{Ch})] /\left[(\mathrm{Cp}) \mathrm{Fe}\left(\mathrm{C}_{6} \mathrm{H}_{6}\right)\right]^{+}$system functions as a (photo)latent drier for the curing of alkyd coatings, performing equally well as the commercial driers NUODEX® Cobalt $10 \mathrm{Neo}$ and NUODEX® DryCoat in terms of drying time and outperforming NUODEX® DryCoat in terms of hardness development, without the need for MEKO as an anti-skinning agent. The newly identified drier is the first system based on an abundant and non-toxic transition metal $(\mathrm{Fe})$ that combines good drying and hardness-values without the need for an anti-skinning agent.

Based on the observed light-dark on/off effect we conclude that photolysis leads to the formation of short-lived active species, explaining the excellent latency. EPR studies suggest that highspin $\left[(\mathrm{Cp}) \mathrm{Fe}^{\prime \prime}(\mathrm{L})\right]^{+} \quad$ species, photo-generated from $\left[(\mathrm{Cp}) \mathrm{Fe}^{\text {ll }}(\text { arene })\right]^{+}$, are involved in the curing process.

Further studies into the hardness development and lightdependency of alkyd curing using $[(\mathrm{Cp}) \mathrm{Fe}(\mathrm{Ch})] /[(\mathrm{Cp}) \mathrm{Fe}(\text { arene })]^{+}$ are currently underway in our group, and we see a bright future for photochemically-derived latency in the (oxidative) crosslinking of coatings.

\section{Acknowledgements}

We thank the ARC-CBBC (project 2016.001.UvA) for financial support. Henk Kelders (AkzoNobel) and Zhi Qhi Hu (AkzoNobel) are thanked for their help with the BK drying time and König hardness value measurements. Felix de Zwart (University of Amsterdam) is thanked for fruitful discussions, in particular w.r.t. the EPR studies.

\section{Conflicts of interest}

J.B., J.F. and B.B. are inventors on PCT International Patent Application WO2021/001410 (to AKZO NOBEL COATINGS INTERNATIONAL B.V.), which claims the use of driers described in this work.

Keywords: (photo-)latency • alkyd curing • cobalt replacement • MEKO-free $\cdot$ high spin (Cp)Fe"l

[1] (a) U. Lüning, Angew. Chem. Int. Ed. 2012, 51, 8163-8165. (b) F.A Leibfarth, K.M. Mattson, B.P. Fors, H.A. Collins, C.J. Hawker, Angew. Chem. Int. Ed. 2013, 52, 199 - 210. (c) Application of Stimuli Responsive and 'Non-innocent' Ligands in Base Metal Catalysis (Chapter 1). A Chirila, B. Gopal Das, P.F. Kuijpers, V. Sinha, B. de Bruin, in Non-Noble Metal Catalysis: Molecular Approaches and Reactions, Wiley Press,
2019 (edited by Klein Gebbink, R.J. \& Moret, M.-E.), ISBN: 978-3-52769908-7.

[2] V. Blanco, D.A. Leigh, V. Marcos, Chem. Soc. Rev. 2015, 44, 5341-5370.

[3] (a) R.S. Stoll, S. Hecht, Angew. Chem. Int. Ed. 2010, 49, 5054-5075. (b) B.M. Neilson, C.W. Bielawski, ACS Catalysis, 2013, 3, 1874-1885.

[4] H. Lai, J. Zhang, F. Xing, P. Xiao, Chemical Society Reviews 2020, 49, 1867-1886.

[5] (a) N. Corrigan, J. Yeow, P. Judzewitsch, J. Xu, C. Boyer, Angew. Chem Int. Ed. 2019, 58, 5170-5189. (b) X. Pan, M. A. Tasdelen, J. Laun, T. Junkers, Y. Yagci, K. Matyjaszewski, Progress in Polymer Science 2016, 62, 73-125. (c) M. Chen, M. Zhong, J. A. Johnson, Chemical Reviews 2016, 116, 10167-10211.

[6] (a) N. Corrigan, S. Shanmugam, J. Xu, C. Boyer, Chem. Soc. Rev. 2016 45, 6165-6212. (b) N. Zivic, M. Bouzrati-Zerelli, A. Kermagoret, F. Dumur, J.-P. Fouassier, D. Gigmes, J. Lalevée, ChemCatChem 2016, 8, 16171631.

[7] (a) M. L. Lepage, C. Simhadri, C. Liu, M. Takoffoli, L. Bi, B. Cawford, A S. Milani, J. E. Wulff, Science 2019, 366, 875-878. (b) F. J. de Zwart, J. Bootsma, B. de Bruin, Science 2019, 366, 800.

[8] A. Hofland, Progress in Organic Coatings 2012, 73, 274-282.

[9] M. D. Soucek, T. Khattab, J. Wu, Progress in Organic Coatings 2012, 73, 435-454.

[10] W. J. Muizebelt, M. W. F. Nielen, Journal of Mass Spectrometry 1996 31, 545-554.

[11] J. Honziček, Ind. Eng. Chem. Res. 2019, 58, 12485-12505.

[12] S. J. F. Erich, Ö. Gezici-Koç, M.-E. B. Michel, C. A. A. M. Thomas, L. G. J. van der Ven, H. P. Huinink, J. Flapper, F. L. Duivenvoorde, O. C. G. Adan, Polymer 2017, 121, 262-273.

[13] European Commission; Environment, Chemicals, REACH (https://ec.europa.eu/environment/chemicals/reach/reach_en.htm, accessed 30 April 2021).

[14] R. Hage, J. W. de Boer, K. Maaijen, Inorganics 2016, 4, 11.

[15] N. Simpson, K. Maaijen, Y. Roelofsen, R. Hage, Catalysts 2019, 9, 825

[16] R. Hage, J. W. de Boer, F. Gaulard, K. Maaijen, R. van Eldik, C. D. Hubbard, Advances in Inorganic Chemistry, Vol. 65, Academic Press, 2013, pp. 85-116.

[17] (a) P. Kalenda, J. Holeček, D. Veselý, Milan Erben, Prog. Org. Coat 2006, 56, 111-113. (b) V. Stava, M. Erben, D. Vesely, P. Kalenda, Phys. Chem. Solids 2007, 68, 799-802. (c) M. Erben, D. Veselý, J. Vinklárek, J. Honziček, J. Mol. Cat. A: Chem. 2012, 13-21.

[18] (a) J. Honziček, J. Vinklárek, J. Appl. Polym. Chem. 2018, 135, 46184 (b) J. Honziček, T. Fedorova, J. Vinklárek, T. Mikysek, I. Císařová, Coatings 2020, 10, 873

[19] R. van Gorkum, E. Bouwman, Coordination Chemistry Reviews 2005 , 249, 1709-1728.

[20] D. Astruc, Tetrahedron 1983, 39, 4027-4095.

[21] Photocrosslinking of epoxy resins. F. Lohse, H. Zweifel in Epoxy Resins and Composites III. Advances in Polymer Science. (Eds. K. Dušek), Springer, Berlin, Heidelberg, 1986, pp. 61-81, ISBN 978-3-540-15936-0.

[22] D. Jones, L. Pratt, G. Wilkinson, J. Chem. Soc. 1962, 4458-4463.

[23] R. A. Brown, A. Houlton, R. M. G. Roberts, J. Silver, E. Slade, J. Chem. Soc. Dalton Trans. 1993, 1519-1523.

[24] A. N. Nesmeyanov, N. A. Vol'kenau, L.S. Shilovtseva, V. A. Petrakova, J. Organomet. Chem. 1975, 85, 365-373.

[25] F. R. van de Voort, A. A. Ismail, J. Sedman, G. Emo, J. Am. Oil. Chem. Soc. 1994, 71, 243-253

[26] T. P. Gill, K. R. Mann, Inorg. Chem., 1983, 22, 1986-1991.

[27] K. R. Mann, A. M. Blough, J. L. Schrenk, R. S. Koefod, D. A. Freedman J. R. Matachek, Pure \& Appl. Chem., 1995, 67, 95-101.

[28] (a) M. Reiners, M. Maekawa, D. Baabe, M.-K. Zaretzke, P. Schweyen, C. G. Daniliuc, M. Freytag, J. Rader, J. Hohenberger, J. Sutter, K. Meyer M. D. Walter, Dalton Trans., 2018, 47, 10517-10526. (b) O. A. Groß, S. Lauk, C. Müller, W. Gidt, Y. Sun, S. Demeshko, F. Meyer, H. Sitzmann, Eur. J. Inorg. Chem., 2017, 30, 3635-3643. (c) M D. Walter, P. S. White Dalton Trans., 2012, 41, 8506-8508. (d) M. Reiners, M. Maekawa, C. G. Daniliuc, M. Freytag, P. G. Jones, P. S. White, J. Hohenberger, J. Sutter, K. Meyer, L. Maron, M. D. Walter, Chem. Sci., 2017, 8, 4108-4122.

[29] Ö. Gezici-Koç, C. A. A. M. Thomas, M.-E. B. Michel, S. J. F. Erich, H. P. Huinink, J. Flapper, F. L. Duivenvoorde, L. G. J. van der Ven, O. C. G. Adan, Materials Today Communications 2016, 7, 22-31.

[30] Z. O. Oyman, W. Ming, R. van der Linde, J. ter Borg, A. Schut, J. H. Bieleman, Surface Coatings International Part B: Coatings Transactions 2005, 88, 269-275.

[31] S. J. F. Erich, J. Laven, L. Pel, H. P. Huinink, K. Kopinga, Prog. Org Coat., 2005, 52, 210-216.

[32] B. Muik, B. Lendl, A. Molina-Díaz, M. J. Ayora-Cañada, Chemistry and Physics of Lipids 2005, 134, 173-182.

[33] G. Ellis, M. Claybourn, S. E. Richards, Spectrochimica Acta Part A Molecular Spectroscopy 1990, 46, 227-241. 


\section{Entry for the Table of Contents}

\section{Light-controlled latency in alkyd curing}

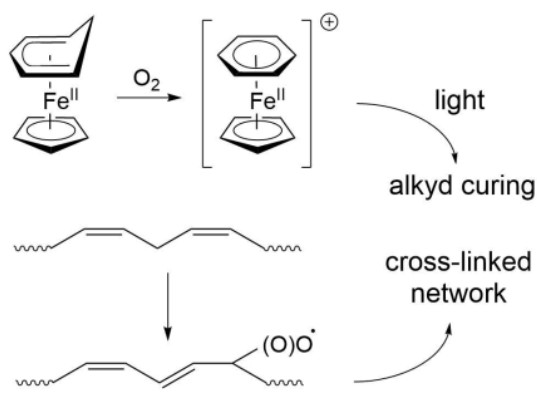

In this study we show for the first time that (volatile) anti-skinning agents are not required in alkyd paint mixtures to prevent premature curing during (long-term) storage. Instead, photochemical latency can provide control over the onset of curing. Physical measurements on paint samples are combined with spectroscopic studies on the curing process (FTIR \& Raman) as well as the photo-activation process of the new iron-based drier (EPR \& NMR).

Institute and/or researcher Twitter usernames: @ARCCBBC, @wesleyrbrowne1, @bruin_bas, @AkzoNobel 